clot and shreds of placenta were removed from the lower half of the uterus - the soft mass“ at the top not being dislodged. The curette was only in use a minute when it was noticed that a yellow fat-like substance came away in one scraping. As the flushing curette was not in working order my assistant passed me the ovum forceps to deal with what we considered the placenta attached to the fundus. It was gently withdrawn and to our extreme surprise was seen to be a coil of the large intestine! It was immediately replaced, and a long saline injection was given through the wound into the abdomen. The patient's pulse had become running and feeble; she was given strychnine and ergotinin hypodermically and the saline injection was continued until she recovered. A strip of gauze was put into the uterus, which was beginning to contract, and the vagina was lightly packed. The patient's condition was not at the moment such as to allow of an immediate laparotomy, so she was taken to the ward and there watched, being given hypodermic injections of strychnine and ergotinin. She was placed with her head lower than her feet for the first hour.

Dr. Agnes C. Scott, of St. Stephen's Hospital, was called in in consultation. The patient's pulse had improved and was full and strong. She was not vomiting unduly and seemed fairly comfortable, so it was decided to push the ergotinin and to place her in Fowler's position; this was done. She gradually improved and was kept on albumin water and white wine whey at first and then began taking milk. Her pain had disappeared and when she had been six days in hospital she felt well enough to want to go home. Meanwhile she was kept in Fowler's position except for a short time on the fifth and sixth days, when her bed was lowered and she was allowed to be raised on pillows. She was having no discharge and no pain ; her temperature was normal and the pulse was good. On the night of the seventh day the night nurse noticed a discharge on the diaper. It was slightly yellow and had a faint odour of digestive fluid. Some pain was felt by the patient in the right iliac region; she was otherwise doing well. A laparotomy was decided on as the discharge continued and made us suspect a rent in the intestine. The patient's pulse on the eighth evening was not very satisfactory. On opening the abdomen it was found that the omentum was closely adherent all round the. lower part, which was completely shut off. It was attached to the brim of the pelvis and, indeed, was so firmly held down that it was decided not to risk opening it. The abdomen was closed and the patient was put to bed. Her condition did not justify the extensive radical and plastic measures that were necessary. Her condition suddenly got worse two days after. The tenderness of which she had complained (before admission) in the right iliac region increased. She was unable to retain anything but albumin water; her pulse got very bad. On the twelfth day after admission she died.

It was discovered later that at her confinement she had an untrained Indian midwife who is one of a class that generally pull on the child and sometimes, to assist labour, stand on the fundus. The patient had been unable to recover her strength after the confinement and had had five attacks of extreme colic in four weeks. The pain was most severe in the right iliac fossa. She was doubled up with it and had romiting and constipation. The pain lasted for from four to six days each time, being acute for about 36 hours.

No post-mortem examination was allowed but from what was seen and felt at the operation the case was one in which there had been a long transverse tear in the fundus (about two inches long at the date of operation). Lying on this tear and protruding into the uterus was a coil of intestine which the subsequent examination proved to have been shut off by the adherent peritoneum. The dislodging of this coil and the contractions of the uterus in which it was, perhaps, again caught may have produced the later symptoms which preceded death.

Delhi.

University of OxFord.-Mr. H. C. Bazett, B.A., Wadham College, was the successful candidate in the recent examination for the Universities' scholarship at St. Thomas's Hospital. Mr. Bazett took a first class in physiology in the final schools last July.

\section{DIFFUSE PAINFUL LIPOMA OF THE FOOT.}

BY A. H. TUBBY, M.S. LOND.,

SURGEON TO WESTMINSTER HOSPITAL AND IN CHARGE OF THE ORTHOP EDIC DEPARTMENT, ETC.

DURING the past ten years some examples of an affection which I believe to be hitherto undescribed have come under my notice. The trouble, although a slight one, yet causes considerable difficulty and pain in walking and from its position mistakes easily arise in diagnosis. I append notes of two cases.

CASE 1.-A hospital nurse, aged 25 years, was admitted to Westminster Hospital on May 24th, 1906. She had been nursing for nine months. Three months previously she first experienced aching pains in the soles and inside of the feet. The pain was worse on rising in the morning and for about an hour afterwards, but it continued to trouble her for the whole day. Almost instantaneous relief was obtained on lying down or resting the foot, but the pain came on again on walking. On examination, on looking at the feet on the inner side and just below the sustentacula tali, an oval swelling was visible on each foot. The growths encroached on the weight-bearing surface of the feet; in size they measured 1 inch by $1 \frac{1}{2}$ inches. Their characters were those of indolent growths, moderately well defined and without signs of inflammation over them. They were painful to the touch and particularly so to deep pressure. The feet were not flat in the ordinary sense of the word. The swellings were diagnosed as diffuse lipoma from an experience of similar cases. An operation was undertaken and when the swellings were incised they were found to be of a fatty nature. They were not encapsuled; but the globules of fat of which they were composed were considerably larger and lighter in colour than the surrounding normal fat, so that there was no difficulty in dissecting away the whole of the growths. It was noticeable that the tumours were highly vascular and bled considerably. The wounds were closed in the ordinary way and healed without difficulty.

Dr. R. G. Hebb, the physician-pathologist to the hospital, made a microscopical examination, and reported that no evidences of nerve endings or of nævoid tissue were found in the tissue, which consisted entirely of fat. The patient presented herself for examination at intervals but the growths did not recur.

CASE 2.-A girl, aged 16 years, was admitted to Westminster Hospital on Jan. 20th, 1906, complaining of pain on the inner side of the right foot which had troubled her for a year. The pain was at its worst after walking but not severe enough to prevent her from getting about. On examination, on the inner side of the right foot there was a round

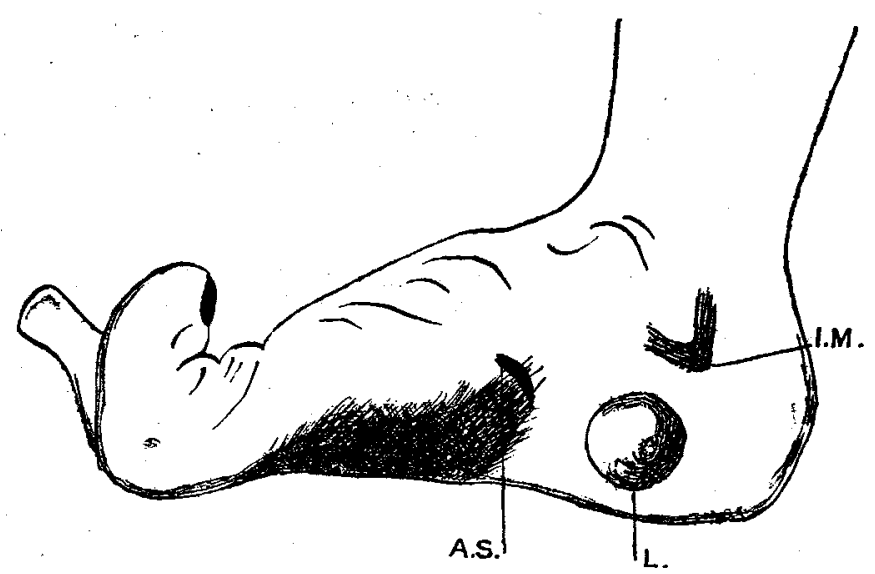

To illustrate the appearanees in Case 2. The position of the lipoma is clearly shown at L., and its relation to the inner longitudinal arch of the foot is evident. I.M., Internal malleolus. A.s., Astragalo-scaphoid joint. The great toe is in a state of temporary spasmodic dorsi-flexion.

semi-cystic swelling about one inch in diameter. The highest point of it was one inch below the tip of the internal malleolus, and the lowest point half an inch above the heel. It presented the same physical characteristics as the tumours in the preceding case and was most prominent when the foot was forcibly dorsi-flexed. The swelling was removed and showed the same fatty and vascular character 
as in the preceding case. When the patient left the hospital she was able to walk without pain.

These cases of acquired diffuse painful lipoma of the foot are clearly distinguishable from that form of "gigantism" known as congenital diffuse lipoma, where the affection is characterised by a general hypertrophy of the fatty and subcutaneous tissues, first affecting the toes or fingers. It spreads by direct continuity for a time; but as the hypertrophy increases, isolated masses of fatty material appear at some distance beyond the advancing edges. In time these masses become incorporated with the advancing growth. Incidentally, I should add that the microscopical characters of the congenital diffuse lipoma are entirely different from those seen in the painful acquired form of diffuse lipoma. In the former, while the main part of the section is occupied by fat and areolar tissue, yet the interfibrous spaces are crowded by small round cells, not unlike those seen in round-celled sarcoma. And clinically the diffuse congenital form of lipoma is somewhat akin to sarcoma in that it shows an inveterate tendency to recur very rapidly after removal. In the acquired diffuse form no such appearances are evident, but the blood-vessels are extremely numerous and somewhat hypertrophied. And in connexion with their origin cases are met with which throw some light on this point. Such an one is the following, occurring in a girl, aged 17 years, which was diagnosed as angioneuroma of the hands. In April, 1907, a swelling formed on the dorsum of the right hand towards the radial side. It was situated over the first and second metacarpal bones and appeared to surround more particularly the extensor tendon of the index finger. The growth was always extremely painful to the touch and sometimes gave her pain even when the part was at rest. The skin over the tumour was hotter than in other parts of the hand, at the centre it was red, but there was a dark bluish discolouration around the circumference. The swelling increased rapidly while she was under observation for a few days previous to operation. A mass of nævoid tissue of about the size of half a crown was excised through a T-shaped incision. Dr. Hebb made the following report on the specimen: "It consists of fibrous and adipose tissue in which are numerous blood-vessels, the arterial walls being extremely thick." The left hand had been similarly affected in January, 1907, when the girl was operated upon by my colleague, Mr. Arthur Evans. In January, 1908, she reappeared at the hospital, as the angiomatous condition had re-formed on both hands. The striking feature of her case was the extreme tenderness, and the parts were so sore that it was impossible to examine them properly. Further, the swellings were hard and appeared hotter to the touch than elsewhere. An operation was undertaken by Mr. E. Rock Carling and a considerable mass of nævoid tissue was dissected from the extensor tendons over which it had spread.

Now in the case of acquired painful lipoma, and in the nævoid condition just described, in which fat was present, we have certain conditions in common-namely, their excessive vascularity, the size and thickness of the vessels, and their extreme tenderness. It is difficult to account for the tenderness. It may be due to irritation of the nervi vasorum. Certainly no nerve fibres or endings could be discovered in the substance of the growths. Whether the acquired diffuse form is due to fatty degeneration of nævoid tissue is not proven, but this possibility should be borne in mind.

We now pass on to certain clinical points. Without careful observation the swellings due to acquired painful diffuse lipoma may partially fill up the arches of the feet, so that the condition can be mistaken for flat foot; but in all the cases I have seen, numbering now five, the tumours have always been between the inner edge of the sole of the foot and the internal malleolus, and have not extended further forward than the anterior part of the sustentaculum tali. In no case have I seen them over the scaphoid or internal cuneiform bone. The striking features about them are their slow growth and their indolence, their extreme tenderness, and their vascularity when cut into. It is also noticeable that any pressure, whether arising from an irregularity on the inside of the boot or from the employment of a "flatfoot" pad, renders the patient completely unable to get about on account of the pain. Finally, on removal, they do not, as far as I know, recur, and in this respect are entirely different from the congenital diffuse lipoma.

Harley-street, W.

\section{SANITATION IN A TERRITORIAL CAMP}

By J. S. WARRACK, M.A., M.D. A Berd., D.P.H. Cantab, CAPTAIN, R.A.M.C. (T.) ; SURGEON-CAPTAIN, A.M.R. (O.); ASSISTANT MEDICAI OFFICER, PORT OF LONDON SANITARY AUTHORITY.

THE following account gives some idea of the methods of sanitation and sanitary training adopted at the Kent Brigade training at Walmer from July 25th to August 8th, 1908 .

On appointment as sanitary adviser to the senior medical officer of the brigade I went over the ground and thought out the best means whereby the sanitation could be carried out so far as possible on the same lines as in the regular forces. I found that the methods used in the Hampshire training and manœuvre area 1907 were most applicable. The troops, over 2000 in number, consisting of four battalions of infantry, a battalion of cyclists, two field ambulances, Army Service Corps, and a cadet battalion (during the second week) were camped on the slope of a hill facing the sea. The formation of the hill was of chalk on the upper two-thirds and of loam on the lower one-third. The camp was divided into two parts by a public street kerbed and channelled. There were open fields to the south and to the north a plantation of trees. On my arrival I found that the camp had been pitched and that deep latrines had been dug on the flanks, which were already foul. The kitchens and the ablution benches adjoined the main street. There were no destructors and no urinals and the refuse tubs were uncovered. The latrines on the south flank were well away from the tents. Those on the north flank were in undesirably close proximity to the tents and the stores and to a public footpath. There was really no other place where they could have been dug. Water was laid on in iron pipes and standpipes were to be found in various convenient positions. It was obvious then that dirty water could be disposed of separately from excreta.

A detailed inspection was made on July 26th. Arrangements were made for inspecting all food supplies, dry canteens, kitchens, horse lines, and the sanitary accommodation generally, and for lectures to be given on sanitation to the troops. An official inspection was made every morning by the senior medical officer and myself, and I paid frequent visits to all parts of the camp at uncertain hours during the first few days.

Food inspection.-The meat supplied throughout was good. On three occasions meat was rejected: (1) a carcass of frozen mutton, which showed signs of recent pleurisy in the pleural cavities; (2) a forequarter of frozen meat which was tainted; and (3) a forequarter of frozen meat supplied instead of home-killed meat. The bread supplied was of good quality. Dry canteens were inspected and all food and comestibles ordered to be covered with muslin or wire-netting. Perishable food supplies were ordered to be kept in cool places and covered up. The cooking arrangements varied from field ovens to portable kitchens, stoves, and boilers. No two units were alike in their cooking arrangements. Messing as regards the battalions was in tents. This I consider to be undesirable, it fouls the ground and attracts flies. There is much unnecessary waste. A large proportion of the contents of the refuse tubs were found to consist of bread, butter, and cooked meat. There is no accommodation in tents for the keeping of rations nor for washing up. The field ambulances and the cadet battalion messed in marquees ; their ground was always free from food refuse and was much easier to keep clean. If attention is given to detail men can be as easily fed in messes in marquees as on transports. They are more comfortable. The ground remains clean and labour is saved in the picking up of scraps and in the washing up afterwards.

Disposal of refuse.-Large tubs or barrels were supplied by a contractor who removed the food refuse periodically. He was required to supply wooden covers for the tubs. This, after a little pressure, he did. The lids, however, were not invariably to be found on the tubs.

Dry refuse.-On my suggestion each unit in the camp built a destructor. These were circular structures 3 feet in height and 2 feet across, with openings at the bottom to admit air. They were made of sods strengthened by wood battens, or of bricks puddled with clay. The plan was shown to the pioneers, and it was left to their ingenuity to carry it out in detail. These destructors worked well ; dry rubbish, tins, \&c., were burnt up, and they lasted all the camp. They were most satisfactory. 